\title{
Thulium-doped Yttria Planar Waveguide Laser Grown by Pulsed Laser Deposition
}

\author{
Jakub Szela, Katherine A Sloyan, Tina L Parsonage, Jacob I Mackenzie, Robert W Eason \\ Optoelectronics Research Centre, University of Southampton, Highfield, Southampton SO17 1BJ, UK
}

Lasers operating in the 2 micron wavelength region are of particular interest for various applications in remote sensing/LIDAR, materials processing, and medical treatments. Thulium-doped media have several attractive features for generating light in this wavelength band, including a broad emission bandwidth, long-lived metastable states, absorption bands matched to high-power $0.8 \mu \mathrm{m}$ diode-pump sources coupled with the potential for high quantum-efficiency due to a 2 -for-1 cross-relaxation process. The sesquioxide crystal family is of considerable interest as a potential host due to their excellent thermo-optic characteristics and spectroscopic properties. A key challenge for this host material is its high-temperature growth requirements (some in excess of $2500 \mathrm{~K}$ for bulk crystals); as such there has been limited success in fabricating these crystals commercially. Here we report the first growth and lasing results (to the best of our knowledge) of a crystalline $\mathrm{Tm}: \mathrm{Y}_{2} \mathrm{O}_{3}$ waveguide, fabricated via pulsed laser deposition (PLD).

A Tm: $\mathrm{Y}_{2} \mathrm{O}_{3}$ film of thickness $\sim 12 \mu \mathrm{m}$ was deposited on a $1 \mathrm{~cm}^{2} \mathrm{Y}_{3} \mathrm{Al}_{5} \mathrm{O}_{12}$ substrate. The PLD source was a $\mathrm{KrF}$ excimer laser, producing $\sim 2 \mathrm{Jcm}^{-2}$ pulses incident upon a Tm:doped ceramic yttria target in an oxygen atmosphere at a gas pressure of $4 \times 10^{-2}$ mbar. During deposition the substrate was heated to $\sim 1000{ }^{\circ} \mathrm{C}$ via a $\mathrm{CO}_{2}$ laser at a wavelength $10.6 \mu \mathrm{m}$, leading to crystalline growth, highly textured in the (222) orientation, as determined via X-ray diffraction. The Tm concentration in the film was determined to be $\sim 2.5$ at. $\%$ by energy dispersive X-ray analysis. Two opposing facets were polished plane and parallel for subsequent laser experiments, leading to a final waveguide length of $8 \mathrm{~mm}$. The fluorescence spectrum was measured from the film's end facet when face pumped by a $795 \mathrm{~nm}$ diode laser, Fig. 1, consistent with that obtained from bulk $\mathrm{Tm}: \mathrm{Y}_{2} \mathrm{O}_{3}[1]$.

Longitudinally pumped by a Ti:sapphire laser tuned to an absorption peak at 797nm, the $\mathrm{Tm}_{\mathrm{Y}} \mathrm{Y}_{2} \mathrm{O}_{3}$ waveguide laser operated around $1951 \mathrm{~nm}$, depending upon the cavity arrangement. An aspheric-lens was used to couple the pump light into the active layer, generating a spot radius of $\sim 4 \mu \mathrm{m}$ at the waveguide facet. Using a thin pump-in-coupling high-reflectance (HR) mirror attached to the input facet and various bulk output coupling mirrors, the best laser performance is shown in Fig. 2. The highest output power was achieved with a bulk 15\% transmitting output coupler mirror positioned in close proximity to the waveguide end facet, giving $35 \mathrm{~mW}$ out for $600 \mathrm{~mW}$ of incident pump power on the pump-coupling lens, and a slope efficiency of $9 \%$. The waveguide propagation loss was determined to be $\sim 2 \mathrm{dBcm}^{-1}$ by measuring the laser's relaxation oscillation frequency at various pump power levels.

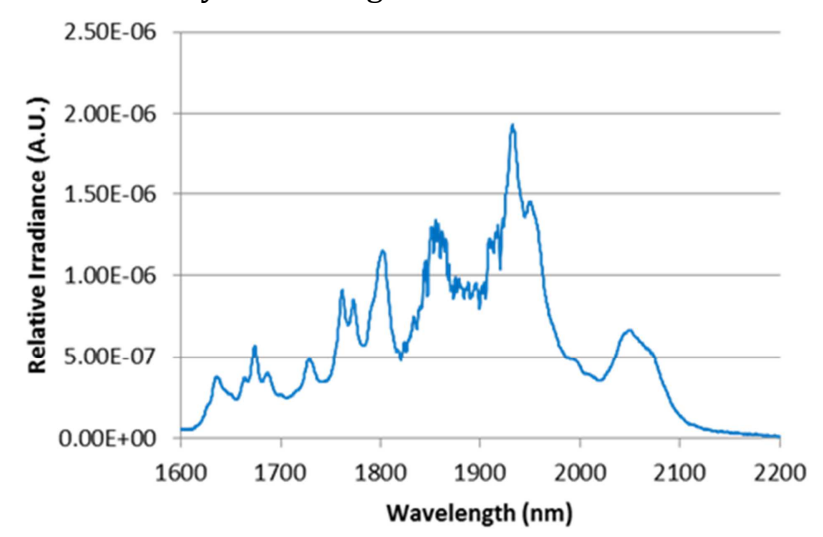

Fig. 1: $\mathrm{Tm}: \mathrm{Y}_{2} \mathrm{O}_{3}$ waveguide fluorescence spectrum.

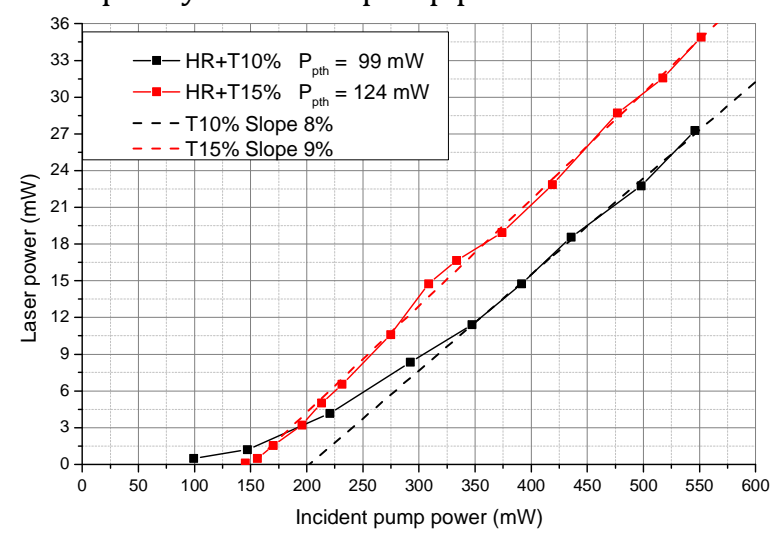

Fig. 2 Laser output power versus incident pump power.

We will discuss the laser performance and growth of this first $\mathrm{Tm}: \mathrm{Y}_{2} \mathrm{O}_{3}$ crystalline waveguide, and further progress in reducing losses and improving the output powers, including growth of multilayer structures for high power operation.

\section{References}

[1] L. Fornasiero, N. Berner, B. Dicks, E. Mix, V. Peters, K. Petermann, and G. Huber, "Broadly Tunable Laser Emission from Tm: $\mathrm{Y}_{2} \mathrm{O}_{3}$ and Tm: $\mathrm{Sc}_{2} \mathrm{O}_{3}$ at $2 \mu \mathrm{m}$," in Advanced Solid State Lasers, M. Fejer, H. Injeyan, and U. Keller, eds., Vol. 26 of OSA Trends in Optics and Photonics (Optical Society of America, 1999), paper WD5. 